\title{
Geobiology of the Ediacaran-Cambrian Transition: ISECT 2017
}

\author{
Special Editors \\ Luke Beranek \\ Department of Earth Sciences \\ Memorial University of Newfoundland \\ St. John's, Newfoundland, Canada \\ Marc Laflamme \\ Department of Chemical and Physical Sciences \\ University of Toronto Mississauga \\ Mississauga, Ontario, Canada \\ Brian Pratt \\ Department of Geological Sciences \\ University of Saskatchewan \\ Saskatoon, Saskatchewan, Canada
}

